\title{
A importância da validação das emoções das crianças
}

\author{
The importance of validating children's emotions \\ La importancia de validar las emociones de los niños
}

Recebido: 31/07/2021 | Revisado: 02/08/2021 | Aceito: 13/08/2021 | Publicado: 16/08/2021

\author{
Joana Barbosa de Souza \\ ORCID: https://orcid.org/0000-0001-9630-9333 \\ Centro Universitário FAMETRO, Brasil \\ E-mail: joanna_souza16@live.com \\ Juliana Castro Ferreira \\ ORCID: https://orcid.org/0000-0002-5631-1145 \\ Centro Universitário FAMETRO, Brasil \\ E-mail: juliana0852castro@gmail.com \\ Julio Cesar Pinto de Souza \\ ORCID: https://orcid.org/0000-0003-3622-1393 \\ Centro Universitário FAMETRO, Brasil \\ E-mail: cmte01@yahoo.com.br
}

\begin{abstract}
Resumo
As crianças estão em uma fase de muito aprendizado, por isso os responsáveis devem ter cuidado sobre o que os infantis estão aprendendo para que possam evitar ou validar certas atitudes/comportamento. Dentro desse aspecto estão as emoções que são fundamentais no desenvolvimento dos pequenos. Diante do apresenta do objetivo geral da pesquisa é destacar a importância de as crianças aprenderem sobre as emoções. A metodologia aplicada possuiu uma abordagem exploratória e qualitativa. Os critérios de inclusão e exclusão aplicado foram estudos publicado a partir do ano de 2016 que investigam a realidade brasileira sobre o tema abordado. Ao final, foram usados 11 estudos onde 9 foram indexadas na plataforma acadêmica SciELO e 2 no google acadêmicos. Nos resultados optaram-se por estudos publicados a partir de 2016 no qual investiguem a realidade brasileira sobre o tema proposto. Conclui-se que a emoção na infância é um processo complexo porque as crianças possuem dificuldade em compreender e expressar o que são sentidos. Quando as crianças não expressão as emoções elas propendem a isolar-se das outras pessoas e desenvolve transtornos como ansiedade, depressão, condutas antissociais, transtornos obsessivo-compulsivos (TOC) e outros distúrbios de comportamento afetando sua vida adulta. Então, logo na infância as crianças devem-se aprender identificar as expressões emocionais.
\end{abstract}

Palavras-chave: Emoções na infância; Distúrbios comportamentais; Regulação emocional.

\begin{abstract}
Children are in a much learning phase, so guardians should be careful about what children are learning so they can avoid or validate certain attitudes/behavior. Within this aspect are the emotions that are fundamental in the development of the small ones. Given the present of the general objective of the research is to highlight the importance of children learning about emotions. The applied methodology had an exploratory and qualitative approach. The inclusion and exclusion criteria applied were studies published from 2016 that investigate the Brazilian reality on the theme addressed. In the end, 11 studies were used where 9 were indexed in the academic platform SciELO and 2 in google academics. In the results, we opted for studies published from 2016 in which they investigate the Brazilian reality on the proposed theme. It is concluded that emotion in childhood is a complex process because children have difficulty in understanding and expressing what they are felt. When children do not express emotions, they propose to isolate themselves from other people and develop disorders such as anxiety, depression, antisocial behaviors, obsessive-compulsive disorders (OCD) and other behavioral disorders affecting their adult life. So as early as childhood children should learn to identify their emotional expressions.
\end{abstract}

Keywords: Emotions in childhood; Behavioral disorders; Emotional regulation.

\section{Resumen}

Los niños están en una fase de aprendizaje, por lo que los tutores deben tener cuidado con lo que los niños están aprendiendo para que puedan evitar o validar ciertasactitudes / comportamiento. Dentro de este aspecto se encuentran las emociones que son fundamentales en el desarrollo de las pequeñas. Dado el presente del objetivo general de la investigación es destacar la importancia de que los niños aprendan sobre las emociones. La metodología aplicada tuvo un enfoque exploratorio y cualitativo. Los criterios de inclusión y exclusión aplicados fueron estudios publicados a partir de 2016 que investigan la realidad brasileña sobre el tema abordado. Al final, se utilizaron 11 estudios donde 9 fueron indexados en la plataforma académica SciELO y 2 en google academics. En los resultados, se optó por 
estudios publicados a partir de 2016 en los que se investiga la realidad brasileña sobre el tema propuesto. Se concluye que la emoción en la infancia es un proceso complejo porque los niños tienen dificultades para entender y expresar lo que se sienten. Cuando los niños no expresan emociones proponen aislarse de otras personas y desarrollar trastornos como ansiedad, depresión, comportamientos antisociales, trastornos obsesivo-compulsivos (TOC) y otros trastornos del comportamiento que afectan a su vida adulta. Así que desde la infancia los niños deben aprender a identificarsus expresiones emocionales.

Palabras clave: Emociones en la infancia; Trastornos del comportamiento; Regulación emocional.

\section{Introdução}

As crianças estão em uma fase de muito aprendizado, por isso os responsáveis devem ter cuidado sobre o que os infantis estão aprendendo para que possam evitar ou validar certas atitudes / comportamento. Dentro desse aspecto estão as emoções que são fundamentais no desenvolvimento dos pequenos. Então, devem ser ensinadas de forma apropriada por educadores, pais e mães ou por profissionais especializados. Consequentemente, é fundamental que todos esses indivíduos conheçam sobre os aspectos das emoções na infância.

A justificativa acadêmica do estudo é apresentar estudos que avaliam os riscos da repressão emocional, como as expressões dos pais influenciam as emoções das crianças e a importância em desenvolver a compreensão emocional na infância com o intuito de apresentar evidências que destaquem a importância de as crianças aprenderem sobre as emoções. Logo, a importância pessoal do estudo é acadêmica porque através da realização dessa pesquisa adquire-se conhecimento técnico e científicos além de acrescentar conhecimento profissional.

Diante do apresenta do objetivo geral da pesquisa é destacar a importância de as crianças aprenderem sobre as emoções. Menciona-se que os objetivos específicos são: compreender o que são emoções; identificar como a expressão emocional dos pais pode afetam a expressão emocional das crianças; explicar os fatores que levam as crianças a reprimirem as emoções e quais seus riscos; e destacar a importância do desenvolvimento e compreensão emocionais na infância.

Para alcançar os objetivos propostos o procedimento metodológico utilizado será de caráter qualitativa, com uma abordagem exploratória. A coleta de dado ocorrerá por meio de pesquisa bibliográfica realizada nas plataformas cientificas SciELO e Google Acadêmico. Para apresentação dos resultados optaram-se por estudos publicados a partir de 2016 no qual investiguem a realidade brasileira sobre o tema proposto.

Espera-se que através da realização do trabalho consiga-se oferecer os responsáveis conhecimento sobre as expressões faciais, nomeação e reconhecimento das emoções, o perigo da repressão das emoções, o papel da regulação emocional na infância que são conhecimento fundamentais no processo de desenvolvimento emocional na infância, uma vez que nessa fase os pequenos possuem pouco ou quase nenhum discernimento sobre o que estão sentido e como expressar tais emoções.

Por fim, o trabalho está estruturado em três capítulos básicos que são a introdução na qual consta assuntos como emoções, expressões dos pais, risco de reprimir as emoções e compreensão emocional. No segundo capítulo trata-se do procedimento metodológico aplicado para alcance dos resultados esperados na pesquisa. O terceiro capítulo apresenta-se os resultados, análise e discussão dos resultados, nessa etapa explora-se 11 estudos que melhor se adequarem aos critérios de inclusão e exclusão com finalidade de atingir resultados confiáveis.

\section{Referencial Teórico}

Educar emocionalmente significa validar emoções, ter empatia com outros, ajudam a identificar e nomear as emoções que estão sendo sentidas, definir limites, ensinar formas aceitáveis de expressão e relacionamento com os outros, amar e aceitar-se, respeitar os outros e propor estratégias resolver problemas (Arruda, 2015). 
As crianças crescem e se desenvolvem rapidamente nos primeiros cinco anos nas quatro principais áreas de desenvolvimento. Essas áreas são motoras (físicas), comunicação e linguagem, cognitivas e sociais e emocionais (Lopes, 2020).

Na primeira infância, regulação emocional começa sendo precário e depende inteiramente de adultos protetores. Por volta dos 8 anos, produz um desenvolvimento cognitivo que torna que as crianças alcançam a autorregulação dede uma forma mais consciente, embora continuará a ser muito importante experiências iniciais e apego estabelecido com os pais (Arruda, 2015).

À medida que a criança amadurece, ela adquire a capacidade de lidar com as demandas sociais, que está ligada não apenas à capacidade de limitar várias manifestações comportamentais e emocionais, mas também à possibilidade de estabelecer outra série de novas associações cognitivas. As crianças devem entender o porquê do que sente e qual seria a reação mais adequada a essa situação, avaliando a forma mais adequada de enfrentar as demandas externas (Pinheiro, 2018).

O desenvolvimento emocional é uma tarefa complexa que começa na infância e continua na idade adulta. As primeiras emoções que podem ser reconhecidas em bebês incluem alegria, raiva, tristeza e medo. Conforme o senso de identidade das crianças se desenvolve, emoções mais complexas como timidez, surpresa, euforia, vergonha, vergonha, culpa, orgulho e empatia emergem. Crianças e jovens em idade escolar ainda estão aprendendo a identificar emoções, a entender por que acontecem e como gerenciá-las de maneira adequada (Franco, Santos, 2015).

As crianças muitas vezes não conseguem desenvolver as emoções facilmente porque muitas vezes não ter palavras para descrever como estão se sentindo. Então, no desenvolvimento emocional dos infantis as emoções positivas, como felicidade, precisam ser incentivadas por meio de elogios, já as emoções negativas como raiva e ansiedade precisam ser tratadas com cuidado e de forma positiva, abraços, calma, distração e paciência (Moitoso, Casagrande, 2017).

Por isso, o desenvolvimento social e emocional positivo é importante, uma vez que, as emoções influenciam a autoconfiança, a empatia, a capacidade de desenvolver amizades e parcerias significativas e duradouras da criança e um senso de importância e valor para as pessoas ao seu redor. O desenvolvimento social e emocional das crianças também influencia todas as outras áreas de desenvolvimento (Lins et al 2015).

Os pais e responsáveis desempenham o papel principal no desenvolvimento social / emocional porque oferecem relacionamentos mais consistentes para seus filhos. Experiências consistentes com familiares, professores e outros adultos ajudam as crianças a aprender sobre relacionamentos e explorar emoções em interações previsíveis (Arruda, 2015).

As estratégias de regulação emocional utilizadas pelos pais são distintas porque tem mães /pais costumam regulação o emocional dos filhos por meios da supressão ou inibição das manifestações emocionais. Em contraponto, existem mães/ pais que tendem a expressar reações emocionais com mais liberdade (Curvello, Mendes, 2020).

A ausência de regulamentação causa um desconforto que dá origem a uma diminuição do desempenho acadêmico e, principalmente, da compreensão de leitura. Isto é porque essa competência requer motivação e processos cognitivos que permitirão processar o código linguístico, interpretá-lo e representá-lo simbolicamente (Alves, 2019).

O objetivo central em relação ao conhecimento emocional é crescer na forma de expressar diferentes emoções, buscando obter consequências satisfatórias relacionadas ao meio que o cerca e consigo mesmo. O processo de socialização proporcionado pelo ambiente próximo, principalmente pelos pais, também possibilita o desenvolvimento de habilidades de socialização e a introjeção de possíveis respostas do ambiente em decorrência de uma resposta anterior da criança (Carvalho, Junior, De Souza, 2019).

Ao analisar os aspectos do desenvolvimento emocional na infância, além da autorregulação, a compreensão emocional e empatia também deve se evidenciar para crianças porque permite conhecer mais especificamente a competência emocional (Franco, Santos, 2015). 
A compreensão emocional como construto tem sido abordada a partir de diferentes concepções teóricas, visto que constitui um eixo central para o desenvolvimento das competências emocionais necessárias à vida. Aguiar et al (2016) apontam que compreensão emocional pode se apresentar em nove níveis: expressão facial, causas externas, desejos, crenças, a influência de uma memória sobre um estado emocional atual, a possibilidade de controlar um estado emocional, a possibilidade de ocultar um estado emocional, experiência, emoç̃os contraditórias e emoções sócio morais.

Conhecimento da compreensão emocional na infância são adquiridos à medida que as crianças compreendem as emoções são geradas e são capazes de reconhecer como essas situações afetam os estados cognitivos e, especificamente, emocionais dos pequenos. Por isso, as crianças com idade escolar não possuem domínio da compreensão emocional por isso precisa, utilizar linguagem especificas para descrever e compreender experiencias emocionais (Chora et al, 2019).

A empatia também deve ser explicada porque é um componente emocional que deve ser alcançado quando a criança para uma melhor compreensão emocional, a compreensão emocional dos outros e a capacidade de regular suas próprias emoções. Estes conceitos destinam-se a situações sociais que permitem, por parte da criança, realizar análises sobre a concretização de objetivos, evidenciar ações afetivas e compreender o porquê de sentir emoções (Moitoso, Casagrande, 2017).

À medida que o menino ou a menina atingem seus objetivos de desenvolvimento, o processo empático obtém reciprocamente possibilidades de ação social, ou seja, o menor atinge níveis mais elevados de análise congruente em relação ao entendimento de uma situação, e como isso pode gerar diferentes manifestações comportamentais em outra pessoa, seja dor, raiva, felicidade, etc (Motta et al, 2017).

A empatia também é um processo de compreensão emocional que permite que várias estratégias de enfrentamento se manifestem, destacando a pessoa envolvida mais do que o próprio sujeito. As experiências emocionais são moldadas com base no indivíduo. Espera-se que à medida que as crianças têm mais experiências, também tenham uma maior capacidade de compreender as várias reações e compreender as suas razões, primeiro em relação a si próprias e depois em relação aos outros (Dutra et al, 2017).

Em suma, compreende-se que problemas emocionais e comportamentais na infância envolvem uma preocupação e um desafio para pais, educadores e profissionais de saúde, ocupando lugar de destaque nas pesquisas sobre transtornos psicopatológicos em crianças.

Geralmente, pais são que têm mais contato com crianças, e aqueles que detectam que algo não está funcionando bem por isso é importante que compreendam esses problemas para oferecer melhor desenvolvimento emocional ou, quando necessário, busque profissionais que possam ajudar.

\section{Metodologia}

A pesquisa é de caráter qualitativa fundamentada na definição de Prodanov (2013, p. 70) considera que há uma relação dinâmica entre o mundo real e o sujeito, isto é, um vínculo indissociável entre o mundo objetivo e a subjetividade do sujeito que não pode ser traduzido em números.

De acordo com Gil (2002) a pesquisa exploratória tem como finalidade proporcionar maior familiaridade com o problema com objetivo de torná-lo mais explícito ou a de construir hipóteses. Possui as formas de pesquisa bibliográfica e estudo de caso.

Tratou-se de uma pesquisa bibliográfica que conforme Lakatos e Marconi (2007) este tipo de pesquisa tem como finalidade colocar o pesquisador em contato direto com tudo que foi escrito, ditou ou filmado sobre determinado assunto.

A pesquisa foi realizada a partir de pesquisas em artigos científicos sobre a temática abordada. Os materiais foram encontrados nas plataformas cientificas SciELO e Google Acadêmico. Para a realização desta pesquisa foi utilizado como 
técnica e instrumento de recolha de dados um fichamento de documentos, o fichamento contém sínteses dos conceitos e pressupostos dos autores sobre o tema (Prodanov, 2013).

Como critério de inclusão para a realização desta pesquisa foram selecionados 11 artigos científicos publicados a partir do ano de 2016. Para a análise de conteúdo seguiu-se as seguintes etapas: 1) Pré-análise: que consistiu na escolha e organização dos textos; 2) Exploração do material: consistiu na elaboração de fichamento dos textos; 3) Tratamento dos resultados: consistiu nas interpretações dos dados. Está técnica de análise dos dados possibilita compreender a mensagem além de seus significados imediatos. (Bardin, 2010 apud Schiavin; Garrido, 2018).

\section{Resultados e Discussão}

\subsection{Resultado}

Neste capítulo, serão apresentados os resultados da pesquisa bibliográfica sistemática efetuada através dos descritores: Emoções, Crianças, e Repressão Psicológica, tomando como referência os artigos publicados entre os anos de 2016 a 2020 nas plataformas SciELO e Google Acadêmico. O Quadro 1 apresenta o número de artigos por periódicos usado para embasamento desse estudo.

Quadro 1 - Número de artigos por periódicos.

\begin{tabular}{|c|c|}
\hline \multicolumn{2}{|c|}{ Bases de dados dos Artigos } \\
\hline SciELO & Google Acadêmico \\
\hline 09 & 02 \\
\hline \multicolumn{2}{|c|}{ Total de 11 artigos } \\
\hline
\end{tabular}

Fonte: Autores (2021).

No Quadro 1, foi contabilizado um quantitativo de 11 artigos como soma das bases de dados pesquisadas, sendo assim, foram encontrados 09 artigos da base de dados SciELO e 03 artigos no Google Acadêmico. O Quadro 2 apresenta o número de artigos publicados por ano usados para embasar esse estudo.

Quadro 2 - Número de artigos publicados por ano.

\begin{tabular}{|c|c|c|}
\hline $\mathbf{N}^{\mathbf{0}}$ & ANO & $\mathbf{N}^{\mathbf{0}}$ DE ARTIGOS \\
\hline 1 & 2016 & 3 \\
\hline 2 & 2017 & 1 \\
\hline 3 & 2018 & 5 \\
\hline 4 & 2019 & 0 \\
\hline 5 & 2020 & 2 \\
\hline
\end{tabular}

Fonte: Autores (2021).

O Quadro 3 apresenta a lista com descrição dos artigos usados no trabalho, no qual foi divido em nome do artigo, nome dos autores, periódico correspondente, ano de publicação e síntese do estudo realizado. 
Quadro 3 - Lista com descrição dos artigos usados no trabalho.

\begin{tabular}{|c|c|c|c|c|c|}
\hline N. & NOME DO ARTIGO & AUTOR & PERIÓDICOS & ANO & SÍNTESE \\
\hline A1 & $\begin{array}{l}\text { Risco e regulação emocional } \\
\text { em idade pré-escolar: A } \\
\text { qualidade das interações }\end{array}$ & $\begin{array}{l}\text { Joana Cadima } \\
\text { Tiago Ferreira } \\
\text { Carolina Guedes } \\
\text { Joana Vieira } \\
\text { Teresa Leal } \\
\text { Paula M. Matos }\end{array}$ & $\begin{array}{c}\text { Google } \\
\text { Acadêmico }\end{array}$ & 2016 & $\begin{array}{c}\text { O artigo trata de investigar as desvantagens } \\
\text { sociais que as crianças enfrentam quando } \\
\text { possuem dificuldades ao nível da regulação } \\
\text { emocional. }\end{array}$ \\
\hline A2 & $\begin{array}{l}\text { Importância das emoções na } \\
\text { aprendizagem: uma } \\
\text { abordagem } \\
\text { neuropsicopedagógica }\end{array}$ & Vitor da Fonseca & SciELO & 2016 & $\begin{array}{l}\text { O artigo procura abordar a importância das } \\
\text { emoções na aprendizagem escolar, tendo em } \\
\text { atenção que a missão da escola atual não deve } \\
\text { ser focada somente no desenvolvimento } \\
\text { intelectual das crianças e dos jovens, mas deve, } \\
\text { igualmente, responsabilizar-se pelo seu } \\
\text { desenvolvimento social e emocional. }\end{array}$ \\
\hline A3 & $\begin{array}{l}\text { Concepções parentais sobre } \\
\text { emoções e o desenvolvimento } \\
\text { emocional de crianças }\end{array}$ & $\begin{array}{l}\text { Roberta Pereira } \\
\text { Curvello } \\
\text { Deise Maria Leal } \\
\text { Fernandes } \\
\text { Mendes }\end{array}$ & SciELO & 2020 & $\begin{array}{l}\text { O artigo analisou as concepções de mães e pais } \\
\text { sobre alegria, tristeza, raiva, medo, orgulho e } \\
\text { vergonha, bem como suas crenças quanto à } \\
\text { importância da manifestação dessas emoções } \\
\text { por crianças, além da articulação com perfis de } \\
\text { autonomia, relação e autonomia-relacionada. }\end{array}$ \\
\hline $\mathrm{A} 4$ & $\begin{array}{l}\text { A importância de nomear as } \\
\text { emoções na infância: relato de } \\
\text { experiência. }\end{array}$ & $\begin{array}{c}\text { Fernanda } \\
\text { Tabasnik } \\
\text { Schwartz } \\
\text { Graziela Pereira } \\
\text { Lopes } \\
\text { Lauren Frantz } \\
\text { Veronez }\end{array}$ & SciELO & 2016 & $\begin{array}{l}\text { O artigo destacou a importância de explicar e } \\
\text { nomear a expressões emocionais para as } \\
\text { crianças com finalidade de trabalhar } \\
\text { autocontrole e expressividade emocional. }\end{array}$ \\
\hline A5 & $\begin{array}{l}\text { Feitos do uso das novas } \\
\text { tecnologias da informação e } \\
\text { comunicação para o } \\
\text { desenvolvimento emocional } \\
\text { infantil: uma compreensão } \\
\text { psicanalítica }\end{array}$ & $\begin{array}{l}\text { Caroline } \\
\text { Cezimbra dos } \\
\text { Santos Jane } \\
\text { Fischer Barros }\end{array}$ & $\begin{array}{l}\text { Google } \\
\text { Acadêmico }\end{array}$ & 2018 & $\begin{array}{l}\text { O artigo propõe a pensar os efeitos que o uso } \\
\text { das novas tecnologias da informação e } \\
\text { comunicação (NTICs) pode ocasionar para o } \\
\text { desenvolvimento emocional infantil, através de } \\
\text { uma compreensão psicanalítica. Além disso, o } \\
\text { artigo discute sobre as possíveis consequências } \\
\text { do uso excessivo dessas tecnologias para o } \\
\text { desenvolvimento emocional da criança. }\end{array}$ \\
\hline A6 & $\begin{array}{l}\text { Mensurando Habilidades } \\
\text { Socioemocionais de Crianças } \\
\text { e Adolescentes: } \\
\text { Desenvolvimento e Validação }\end{array}$ & $\begin{array}{c}\text { Bruno Figueiredo } \\
\text { Damásio }\end{array}$ & SciELO & 2017 & $\begin{array}{c}\text { O artigo realiza um procedimento de criação e } \\
\text { as propriedades psicométricas de seis } \\
\text { instrumentos de avaliação de Habilidade } \\
\text { Socioemocionais. As escalas foram } \\
\text { desenvolvidas para mensurar o Programa } \\
\text { Semente que desenvolve a aprendizagem de } \\
\text { habilidades socioemocionais. }\end{array}$ \\
\hline A7 & $\begin{array}{l}\text { Manejo dos pais frente à } \\
\text { expressão de raiva dos filhos. }\end{array}$ & $\begin{array}{l}\text { Bruna Patrycia } \\
\text { Waligura de } \\
\text { Oliveira } \\
\text { Ana Karoline } \\
\text { Gomes Gurtat } \\
\text { Aline Henriques } \\
\text { Reis } \\
\end{array}$ & SciELO & 2018 & $\begin{array}{l}\text { O artigo objetivou-se investigar o manejo dos } \\
\text { pais frente à expressão da emoção raiva dos } \\
\text { filhos do sexo masculino e feminino. }\end{array}$ \\
\hline A8 & $\begin{array}{l}\text { Escala Crenças Parentais } \\
\text { sobre Competência } \\
\text { Emocional em Crianças } \\
\text { (COMPE): Propriedades } \\
\text { Psicométricas }\end{array}$ & $\begin{array}{l}\text { Deise Maria Leal } \\
\text { Fernandes } \\
\text { Mendes } \\
\text { Pedro P. Pires } \\
\text { Ana Carolina } \\
\text { Monnerat } \\
\text { Fioravanti } \\
\end{array}$ & SciELO & 2020 & $\begin{array}{l}\text { O artigo apresenta as etapas de construção da } \\
\text { escala } \\
\text { Competência Emocional em Crianças e } \\
\text { verificar os parâmetros psicométricos } \\
\text { preliminares como dimensionalidade e } \\
\text { confiabilidade da expressão emocional, } \\
\text { compreensão emocional e regulação emocional }\end{array}$ \\
\hline A9 & $\begin{array}{l}\text { Compreensão emocional em } \\
\text { crianças e crenças maternas } \\
\text { sobre competência emocional }\end{array}$ & $\begin{array}{l}\text { Ana Beatriz de } \\
\text { Mota e Souza } \\
\text { Deise Maria Leal } \\
\text { Fernandes } \\
\text { Mendes }\end{array}$ & SciELO & 2018 & $\begin{array}{l}\text { O artigo examinou a compreensão emocional } \\
\text { em crianças e sua relação com crenças } \\
\text { maternas sobre competência emocional e } \\
\text { contribuiu para a ampliação da discussão } \\
\text { acerca das crenças parentais e da importância } \\
\text { das emoções para o desenvolvimento infantil. }\end{array}$ \\
\hline A10 & $\begin{array}{l}\text { Relação entre autoconceito e } \\
\text { autocontrole comparados ao } \\
\text { desempenho escolar de } \\
\text { crianças do ensino }\end{array}$ & $\begin{array}{l}\text { Gabriella Conte } \\
\text { Sylvia Maria } \\
\text { Ciasca } \\
\text { Iuri Victor } \\
\end{array}$ & SciELO & 2018 & $\begin{array}{c}\text { O artigo identificou a relação entre } \\
\text { autoconceito e autocontrole comparados ao } \\
\text { desempenho escolar em crianças cursando o } \\
\text { Ensino Fundamental I } \\
\end{array}$ \\
\hline
\end{tabular}




\begin{tabular}{|c|c|c|c|c|c|}
\hline & fundamental & Capelatto & & & \\
\hline A11 & $\begin{array}{l}\text { Estratégias de aprendizagem e } \\
\text { a regulação da emoção no } \\
\text { Ensino Fundamental }\end{array}$ & $\begin{array}{c}\text { Adriana Cristina } \\
\text { Boulhoça Suehiro } \\
\text { Evely } \\
\text { BoruchovitchII } \\
\text { Patrícia Waltz } \\
\text { Schelini }\end{array}$ & SciELO & 2018 & $\begin{array}{c}\text { O artigo caracterizou o uso de estratégias de } \\
\text { aprendizagem e de regulação emocional de } \\
\text { crianças brasileiras do Ensino Fundamental, } \\
\text { examinar se existem diferenças nessas } \\
\text { variáveis em razão do sexo, ano escolar e idade } \\
\text { dos estudantes, bem como explorar possíveis } \\
\text { relacões entre elas. }\end{array}$ \\
\hline
\end{tabular}

Fonte: Autores (2021).

\subsection{Discussão}

Para análise de dados foram usados 11 artigo, especificado no quadro 3, que atendem aos objetivos da pesquisa e as critério de inclusão. Diante do exposto, elucida-se que nos estudos utilizados os principais resultados encontrados abordavam sobre a compreensão das emoções, a importância das expressões emocionais dos pais na regulação emocionais das crianças, os fatores que levam as crianças a reprimirem as emoções e quais seus riscos e a importância do desenvolvimento e compreensão emocionais na infância.

\subsubsection{Compreender o que são emoções}

Oliveira, Gurtat e Reis (2018) explicam que as emoções transcorrerem de situações ambientais que geram alterações reações automáticas e expressões faciais decorrente ao ocorrido. Existem um consenso da existência de cinco emoções básicas: medo, tristeza, raiva, nojo e alegria.

Para Fonseca (2016) as emoções são estados emocionais muito importante para todo os seres humanos, principalmente para as crianças uma vez que nessa fase influencia como esse infantis adquirem memorias emocionais que ajudam os infantis a observá-las de formas mais clara e relevante. Por isso é importante que aprendam o papel que cada uma desempenha, para que não se sintam oprimidas e sejam capazes de manejá-las corretamente.

No estudo de Schwartz, Lopes, Veronez (2016) é enfatizado que os pais são os principais responsáveis pelo desenvolvimento das emoções dos filhos porque a família marcar sua identidade pessoal e social. Então, eles devem proporcionar um ambiente e uma educação emocionalmente saudável, e essa atenção deve ser maior nos primeiros anos vida de criança no contexto familiar. Porque com a devido regulação emocional as crianças conseguem adquirir respostas adequadas com o meio ambiente.

A emoção possui papel relevante no desenvolvimento cognitivo das crianças. Nesse sentido, Damásio (2017) elucida que existem uma gama variada de programas que intervém no desenvolvimento de habilidades socioemocionais (HSE) porque o aprimoramento dessas habilidades influencia o funcionamento psicológico, social e educacional. Segundo dados da pesquisa realizada crianças com HSE apresentaram desempenho acadêmico 11\% maior.

Conte, Ciasca e Capelatto (2018), nos resultados apresentados em sua pesquisa, conclui que quando a criança conhece a si mesma e suas emoções apresentam melhor desempenho escolar tem mais capacidade em lidar com as situações do dia a dia.

Os autores como Fonseca (2016), Schwartz, Lopes, Veronez (2016), Damásio (2017) e Conte, Ciasca e Capelatto (2018) concordam que as emoções tem papeis fundamentais na vida das crianças porque influencia toda sua vida porque influenciam a sua capacidade de regular, raciocinar, memorizar e tomar decisões na hora da aprendizagem, o modo como se comporta na sociedade e como lidam com os obstáculos e frustações. Devido sua importância é essencial que os pequenos aprendam como administrá-las. 


\subsubsection{Como a expressão emocional dos pais pode afetam a expressão emocional das crianças}

No estudo de Mendes e Ramos (2020) é apontado que os pais atuam como agentes de socialização, promovendo o desenvolvimento emocional dos filhos, ou seja, os responsáveis têm papeis ativos no emocionais dos seus filhos. Portanto, a expressão emocional serve de reflexo como as crianças encarar o desenvolvimento emocional. O que por sua vez contribui no comportamento compartilhados pelo grupo social a que pertencem, mas também moldados com base em peculiaridades individuais.

A infância é quando ocorrer e observa-se grandes mudanças no conjunto de emoções e a forma como são manifestadas. Destacar a importância das mães e dos pais nessa fase é essencial, principalmente quando falasse no avanço das expressões emocionais das crianças, pois os responsáveis ajudam a compor o quadro compreensivo de aspectos da parentalidade que impactam o desenvolvimento emocional da criança (Mendes, Ramos, 2020).

Para Schwartz, Lopes, Veronez (2016) a capacidade na infância de identificação de expressões emocionais auxilia na competência social, no desenvolvimento cognitivo e é um indicador preciso do ajustamento psicossocial. Entretanto, a ausência dessa capacidade pode implicar um baixo repertório social sintoma de problemas psicológicos e baixa capacidade cognitiva.

A emoção e expressão de raiva dos pais são as que mais impacta o comportamento dos filhos, porque quando uma criança convive em ambiente hostil que vivência brigas e discussão constantes entre irmãos, familiares e/ou amigos o processo psicológico dos infantis, em respostas, tende a ser de luta, autodefesa ou fuga. Dificuldades no gerenciamento da raiva podem piorar o funcionamento social e gerar problemas de comportamento. Portanto, a expressão emocional está diretamente relacionada ao comportamento emocional das crianças (Oliveira, Gurtat, Reis, 2018).

Curvello e Mendes (2020), Schwartz, Lopes, Veronez (2016) e Oliveira, Gurtat e Reis (2018) concordam que as emoções dos pais, e consequentemente as suas expressões faciais, influência como as crianças entendem as emoções. Devido sua importância é fundamental que os pais saibam como expressar suas emoções da melhor forma possível, pois quando não ensinado de modo correto muitas vezes as crianças tendem a reprimir as emoções devido a forma como foram ensinadas.

4.2.2. Os fatores que levam as crianças a reprimirem as emoções e quais seus riscos.

chwartz, Lopes, Veronez (2016) afirma que as crianças possuem dificuldade na nomeação e reconhecimento das emoções. Existem diferentes fatores que os infantis aos não desenvolvimento da capacidade emotivas como a falta de conhecimento das expressões e compreensão emocional que podem ser ensinadas, principalmente, pelos responsáveis.

Souza e Mendes (2018) esclarece em seu estudo que os pais são agentes primários de socialização dos filhos. Como os pais pensam e agem sobre as emoções impacta diretamente o desenvolvimento da criança. Então, quando os pais reprimem as próprias emoções ou ensina suas crianças a reprimi-las esse infantis que estão em processo de construção leva-os a terem dificuldade no desenvolvimento cognitivo, social e emocional.

A repressão das emoções influência também nos resultados acadêmicos das crianças como é demostrado no estudo de Suehiro, Boruchovitch, Schelini (2018) porque as crianças não sabem lhe dar de forma adequada com tristeza, raiva, vergonha, humilhação e tédio, entre outras incidem na forma em situações de aprendizagem e como elas a afetam, ou seja, reduzindo os resultados acadêmicos desses alunos.

Além disso, a repressão das emoções incide em doenças psicológicas como transtornos de ansiedade, distúrbios de comportamentos, condutas antissociais, transtornos obsessiva-compulsivos (TOC), depressão e suicídio (SANTOS, BARROS, 2018).

A compreensão emocionais na infância vem sendo muito debatida na psicologia devido as demandas de habilidades sociais, autocontrole e a expressividade emocional necessários para saber lidar com os próprios sentimentos. Nesse sentido, 
Schwartz, Lopes, Veronez (2016) explica que as crianças precisam ser ensinadas sobre as próprias emoções que, dependendo da faixa etária, pode se iniciar com a nomeação dos próprios sentimentos e no recomento das expressões faciais.

Souza e Mendes (2018), Suehiro, Boruchovitch, Schelini (2018), Schwartz, Lopes, Veronez (2016), e Santos e Barros (2018) apontam que os fatores que levam as crianças a reprimir as emoções são falta de conhecimento das expressões e compreensão emocional, bem como o uso desregulado da tecnologia. O que muito leva ao desenvolvimento de doenças psicológicas como ansiedade e depressão.

\subsubsection{A importância do desenvolvimento e compreensão emocionais na infância}

Oliveira, Gurtat e Reis (2018) salientam que o aprendizado sobre o manejo das emoções deve se iniciar na infância e os pais contribuem para o desenvolvimento da habilidade de Regulação Emocional (RE) das crianças por serem o seu sistema mais próximo de convívio e quando uma criança aprender a RE o manejo de sentimento complexos como a raiva são mais fáceis.

Cadima et al (2016) destacou o papel da regulação emocional na infância. Conforme resultados obtidos em sua pesquisa realizada foi evidenciado que as crianças com capacidade de regulação emocional têm mais interações de qualidade em diferentes níveis emocionais. Entretanto, os infantis com labilidade emocional apresentam maiores dimensões negativas e positivas da regulação emocional, o que influência sua capacidade a capacidade de adaptação, aprendizagem e como lidam com conflitos.

$\mathrm{O}$ advento da tecnologia implicou nas mudanças de diferentes esferas de comportamento dos seres humanos incluindo na forma como lidam e aprendem sobre emoções. Nesse sentido, Santos e Barros (2018), realizou um estudo no qual enfatizou como a tecnologia mudou como as crianças passam seu tempo brincando e se relacionam. Segundo o autor o feito da tecnologia no desenvolvimento emocional pode ser negativo e positivo.

O efeito negativo nas emoções das crianças é quando o excesso do uso de tecnologias ocasiona maior probabilidade de dificuldades no diálogo, isolamento nos contatos e conexões afetivas, falta de comunicação e afeto nas famílias além da dificuldade em tolerar frustrações. Entretanto, o efeito positivo nas emoções das crianças é quando usado de forma correta por pais e profissionais porque podem ser uma ferramenta que auxilia e ensina sobre a compreensão e expressão das emoções (Santos, Barros, 2018).

O ensino para as crianças sobre as emoções devem estar ligado habilidades de discernir seus estados emocionais e dos outros. Para isso, Mendes, Pires e Fioravanti (2017) elucida que competência emocional de crianças pode ser focalizados três grandes pilares: a expressão emocional, a compreensão de emoções e regulação emocional.

A expressão emocional refere-se compreensão observáveis na face, voz, corpo e nível interno ou externo que provoque uma emoção. A compreensão de emoções relaciona-se com a capacidade para identificar emoções em si mesmo e nas outras pessoas e saber nomeá-las adequadamente e a regulação emocional têm relação com capacidade para lidar com emoções, sejam as prazerosas ou as angustiantes, e com as situações que as promovem (Mendes, Pires, Fioravanti, 2017).

Diante da importância do desenvolvimento e compreensão emocionais na infância Damásio (2017) destaca que devem ser implementadas políticas públicas no sistema educacional de ensino que trabalhem o desenvolvimento das competências emocionais em crianças. Para que no futuro tenham mais atitudes positivas em relação a si mesmo, melhores relacionamentos interpessoais, desempenho escolar e saúde mental.

Oliveira, Gurtat e Reis (2018), Cadima et al (2016), Santos e Barros (2018), Mendes, Pires e Fioravanti (2017) e Damásio (2017) concordam que quando as crianças não conseguem compreender e expressar as emoções de maneira apropriada influência o seu comportamento e abre espaço ao desenvolvimento de transtornos psicológicas. Por isso é 
importante que os infantis, desde os anos iniciais aprendam com pais e educadores, sobre as emoções para que consigam compreender e expressar de maneira apropriada.

Como evidenciado na pesquisa o desenvolvimento emocional é vital para ajudar as crianças a se tornarem adultos bem ajustados e capaz de identificar diferentes sentimentos, expressá-los (por meio de palavras / imagens) e processar as emoções difíceis permite que sejam pessoas saudáveis emocional e psicologicamente. Entretanto, para construir essa base para o sucesso social e acadêmico, as crianças pequenas precisam desenvolver competência emocional, ou seja, a regulação da expressividade e experiência emocional, e conhecimento das próprias emoções e das emoções dos outros.

\section{Considerações Finais}

Como explorado ao longo do trabalho as emoções são estados complexos que têm um papel fundamental para a saúde mental das crianças por isso o manejo deve ser logo iniciar na infância porque tem impacto na qualidade de vidas quando adultos. Logo, os infantis devem ser ensinados sobre as emoções para que consigam discernir seus estados emocionais e dos outros. Nesse viés, os pais são responsáveis direto porque convivem diariamente e por isso podem oferecer melhor orientações emocional sobre os contextos vivenciados por eles.

A pesquisa contribuiu com informações novas e relevantes a respeito da importância de as crianças aprenderem regular as emoções, pois quando não orientada ainda nessa etapa da vida pode influenciar os processos mentais e físicos dos infantis. As informações obtidas poderão servir como base para auxiliar novos estudos a respeito do tema, bem como colaborar no desenvolvimento e crescimento profissional.

A metodologia aplicada possuiu uma abordagem exploratória e qualitativa. Os critérios de inclusão e exclusão aplicado foram estudos publicado a partir do ano de 2016 que investigam a realidade brasileira sobre o tema abordado. Ao final, foram usados 11 estudos onde 9 foram indexadas na plataforma acadêmica SciELO e 2 no google acadêmicos.

Os resultados iniciais evidenciado no estudo destacou que a emoção na infância é um processo complexo porque os pequenos possuem dificuldade em compreender e expressar o que são sentidos e quando não regulado na infância podem levar aos desenvolvendo de transtornos mentais. Então, logo na infância as crianças devem-se aprender identificar as expressões emocionais.

O estudo destacou que os pais são os principais responsáveis na validação das emoções das crianças, pois são com eles que convivem diariamente e para os infantis são exemplos a serem seguidos. Em vista disso, quando os pais conversam e ensino sobre as emoções os filhos executam de modo apropriado, mas quando os pais não exercitam esse diálogo e não os ensina-os os infantis tendem a reprimir as emoções devido a forma como foram ensinadas.

Por último, a pesquisa demostrou os fatores que levam as crianças a reprimirem as emoções são ausência de conhecimento para que consigam compreender e expressar a emoções, o uso desregulado da tecnologia porque limitam sua convivência com outras pessoas e, como exposto no parágrafo acima, a falta de validação por partes do reesposeis.

Quando as crianças não expressão as emoções elas propendem a isolar-se das outras pessoas e desenvolvem transtornos como ansiedade, depressão, condutas antissociais, transtornos obsessivo-compulsivos (TOC) e outros distúrbios de comportamento afetando sua vida adulta.

Para pesquisas futuras sugere-se pesquisa aplicadas no qual investiguem as dificuldades que os pais e responsáveis possuem em ensinar os filhos sobre as emoções que podem ser por pouco conhecimento sobre o assunto, estigmas da sociedade que não influenciam o diálogo familiar, entre outros. Além disso, pode-se também analisar a perspectiva das crianças com relação as emoções que podem ocorrer por meio de conversas que devem ser acompanhados com responsáveis. 


\section{Referências}

Aguiar, J. S. R., de Paiva Silva, A. I., Aguiar, C. S. R., Torro-Alves, N., \& De Souza, W. C. (2016). A influência da intensidade emocional no reconhecimento de emoções em faces por crianças brasileiras. Universitas Psychologica, 15(5).

Alves, V. C. T. (2019). Práticas educativas e competências emocionais na primeira infância (Doctoral dissertation).

Arruda, B. B. (2015). Emoções e perturbação emocional: reconhecimento de expressões faciais (Doctoral dissertation, [sn]).

Cadima, J., Ferreira, T., Guedes, C., Vieira, J., Leal, T., \& Matos, P. M. (2016). Risco e regulação emocional em idade pré-escolar: A qualidade das interações dos educadores de infância como potencial moderador. Análise Psicológica, 34(3), 235-248.

Carvalho, C. G., Junior, D. J. C., \& de Souza, G. A. D. B. (2019). Neurociência: uma abordagem sobre as emoções e o processo de aprendizagem. Revista da Universidade Vale do Rio Verde, 17(1).

Chora, M., Monteiro, L., Ramos, M., \& Amaral, R. (2019). Um olhar sobre o papel do pai na compreensão emocional das crianças: Os estilos parentais e práticas de socialização das emoções negativas. Um olhar sobre o papel do pai na compreensão emocional das crianças: os estilos parentais e práticas de socialização das emoções negativas, (33), 19-32.

Conte, G., Ciasca, S. M., \& Capelatto, I. V. (2016). Relação entre autoconceito e autocontrole comparados ao desempenho escolar de crianças do ensino fundamental. Revista Psicopedagogia, 33(102), 225-234.

Curvello, R. P., \& Mendes, D. M. L. F. (2020). Estratégias de regulação emocional de pais: uma revisão da literatura. Psicologia Clínica, $32(2)$, 231-250.

Damásio, B. F. (2017). Mensurando habilidades socioemocionais de crianças e adolescentes: Desenvolvimento e validação de uma bateria (Nota Técnica). Trends in Psychology, 25, 2043-2050.

Dutra, M. P., dos Santos Bezerra, V. A., Silva, A. S., Abreu, G. A., \& de Sousa Galvão, L. K. (2017). Empatia e comportamento pró-social: intervenção educacional na infância. In IV Congresso Nacional de Educação. João Pessoa-PB. Anais IV CONEDU (Vol. 1).

Fonseca, V. D. (2016). Importância das emoções na aprendizagem: uma abordagem neuropsicopedagógica. Revista Psicopedagogia, 33(102), 365-384.

Franco, M. D. G. S. D. E. C., \& Santos, N. N. (2015). Desenvolvimento da compreensão emocional. Psicologia: Teoria e pesquisa, 31 , $339-348$.

Gil, A. C. (2002). Como elaborar projetos de pesquisa (4, 175). Atlas.

Lins, Z. M. B., Salomão, N. M. R., Lins, S. L. B., Carneiro, T. F., \& Eberhardt, A. C. (2015). O papel dos pais e as influências externas na educação dos filhos. Revista da SPAGESP, 16(1), 43-59.

Lopes, I. R. R. (2020). Desenvolvimento social e afetivo na primeira infância: concepções de professoras. Revista Caparaó, 2(2), e24-e24.

Lakatos, E. M., \& Marconi, M. D. A. (2007). Técnicas de Pesquisa. (5a ed.), Atlas.

Mendes, D. M. L. F., \& Ramos, D. D. O. (2020). Concepções parentais sobre emoções e o desenvolvimento emocional de crianças. Psicologia: Teoria e Pesquisa, 36 .

Mendes, D. M. L. F., Pires, P. P., \& Fioravanti, A. C. M. (2018). Escala Crenças Parentais sobre Competência Emocional em Crianças (COMPE): Propriedades Psicométricas. Trends in Psychology, 26, 1819-1832.

Moitoso, G. S., \& Casagrande, C. A. (2017). O desenvolvimento da empatia na infância: fatores implicados. SEFIC 2016.

Motta, D. D. C., Dias, A. P., Carvalho, A. L. N., Castro, R. V. D., Manhães, A. C., Silva, L. G. G., \& Santos, K. N. V. D. (2017). Programa para a promoção da empatia em sala de aula. Revista Brasileira de Terapias Cognitivas, 13(2), 122-130.

Oliveira, B. P. W. D., Gurtat, A. K. G., \& Reis, A. H. (2018). Manejo dos pais frente à expressão de raiva dos filhos. Psico-USF, $23,279-293$.

Pinheiro, M. J. S. (2018). (Des) regulação emocional na adolescência: estratégias de regulação e problemas emocionais e de comportamento (Doctoral dissertation).

PRODANOV, Cleber Cristiano. Metodologia do Trabalho Científico: Métodos e Técnicas da Pesquisa e do Trabalho Acadêmico. (2a ed.), Feevale, 2013.

Santos, C. C., \& Barros, J. F. (2018). Efeitos do uso das novas tecnologias da informação e comunicação para o desenvolvimento emocional infantil: uma compreensão psicanalítica.

Schiavini, J. M., \& Garrido, I. (2018). Análise de Conteúdo, Discurso ou Conversa? Similaridades e Diferenças entre os Métodos de Análise Qualitativa. Revista ADM. MADE, 22(2), 01-12.

Schwartz, F. T., Lopes, G. P., \& Veronez, L. F. (2016). A importância de nomear as emoções na infância: relato de experiência. Psicologia Escolar e Educacional, 20, 637-639.

de Mota, A. B., \& Mendes, D. M. L. F. (2018). Compreensão emocional em crianças e crenças maternas sobre competência emocional. Psicologia Clínica, 30(3), 541-559.

Suehiro, A. C. B., Boruchovitch, E., \& Schelini, P. W. (2018). Estratégias de aprendizagem e a regulação da emoção no Ensino Fundamental. Estudos Interdisciplinares em Psicologia, 9(3), 90-111. 